\title{
FREEWAT - FREE and open source software tools for WATer resource management: an Horizon 2020 for promoting innovative ICT tools in water management
}

\author{
Iacopo Borsi \\ TEA Sistemi SpA - iacopo.borsi@tea-group.com \\ Rudy Rossetto \\ Istituto Scienze della Vita, Scuola Superiore Sant'Anna - r.rossetto@sssup.it \\ Laura Foglia \\ Institute of Geosciences, Technical University Darmstadt - foglia@geo.tu-darmstadt.de
}

Decisions on water management and planning, taken to practically apply the Water Framework Directive (WFD) and water related directives requirements, are often made on geographically lumped 20/30 years average water budgets. These do not consider both the spatial variability of the various hydrological factors and the time variability of the hydrological variables within the year. Moreover, they do not allow the solutions of localized problems, such as aquifer overdraft or exploitation, as they are not able to provide local and timebased solutions. Consequently, results are highly qualitative (semi-quantitative) and not really useful for water management and planning.

The Water Framework Directive 2000/60/CE required an increase of monitoring activities on water quantity and quality; this in turn led to the availability of time series that allow the implementation of more efficient water management tools. Up to now, the information content of such data is not properly exploited, because they are often analyzed with very simple algorithms providing limited insight into the dynamic of the systems. The availability of ICT-tools performing spatially and temporally based analysis will greatly help to exploit the information content of such data and to get a better insight on water bodies behavior.

Although the use of GIS in water management is nowadays widespread and well standardized (see CIS Guidelines 9 and 22), many water authorities still rely on professionals (geologists, geographers, biologists, engineers, etc.) with limited capabilities on the use of new technologies especially dedicated to water management, such as modelling. The same often applies for water utilities or private companies. This constitutes a limit to the challenges and problems posed by water management.

The value of using advanced technologies (often referred as "complex" in WFD related documents) in water management is often diminished by the fact that only well-trained practitioners and professionals are involved in the study and present the results to stakeholders. The latter are not actively involved in the model development and have to rely and trust who performed the analysis (Refsgaard et al. 2010). In this sense, the lack of participatory approach in using advanced ICT tools for evidence-based decisions in water management constitutes a limit to the application of the water related Directives.

From a technical and social point of view, this results in poor coordination among technical and scientific personnel, policy and decision makers, and the various stakeholders involved in the monitoring and management of the water resource.

To overcome this purely technical approach in dealing with very complex water related issues with a large variety of stakeholders involved, it is necessary to introduce the participatory approach. The non-technical aspects of water resource systems (such as societal, political and legal concerns) are recognized as having a great, if not fundamental, importance to reaching an agreed-upon decision; these are therefore to be integrated into the more technical and mathematical issues (SonciniSessa, Weber \& Castelletti 2007).

FREEWAT is an HORIZON 2020 (Fig. 1) project financed by the EU Commission under the call Water Innovation: Boosting Its Value For Europe and coordinated by Scuola Superiore SantAnna, Pisa, Italy (Grant Agreement 62224), started in April 2015. The general objective is to promote water management and planning by simplifying the application of the WFD, Groundwater Directive (GWD), Nitrates Directive (NiD) and other water related Directives. The simplification is achieved through the FREEWAT platform and its participatory approach. The main project result will be an open source and public domain GIS integrated modelling environment for the simulation of water quantity and quality in surface water and groundwater with an integrated water management and planning module.

The FREEWAT project aims at improving Water Resource Management (WRM) by achieving some specific objectives, for instance: to integrate existing software modules for water management in a single environment, the GIS based FREEWAT platform; to support the FREEWAT application in an innovative participatory approach; to build knowledge and capacity in the use of scientific software technologies; optimizing the use of water resource monitoring data; building a web based community of users and developers of the free and open source FREEWAT platform.

A strong capacity building plan will be include, having an expected target of about 1000 individuals from (at least) 180 different stakeholder communities. A dedicated dissemination and exploitation plan will further widen the audience (non-technical one also) reaching up to a minimum of 10000 individuals worldwide. 
The FREEWAT Consortium is constituted by 17 partners from 10 European countries (Italy, Germany, Spain, France, Greece, Estonia, Romania, Malta, Czech Republic, Slovenia, The Netherlands, Switzerland) plus Turkey and Ukraine. UNESCO international organization is also member of the partnership. The consortium is composed of a broad spectrum of research, private companies and authority institutions, including 6 SMEs, 2 authorities, 5 universities, 2 research institutes, 1 not-for-profit research and International training center and 1 International organization.

The overall structure of the FREEWAT (Rossetto R., Borsi I., Foglia L. 2015,) project is based on: i) coordinating previous national and EU funded research to create the FREEWAT platform; ii) supporting capacity building around the FREEWAT platform by means of dedicated training and case studies implementation, in partner's country and at the international level; iii) supporting the FREEWAT application in an innovative participatory approach, that gathers technical staff, and relevant stakeholders in the development and simulation of scenarios for the application of appropriate water policies; iv) promoting dissemination and exploitation, and communication on the FREEWAT activities and results at international level in order to foster its wide application at

Acknowledgments: FREEWAT project has received funding from the European Union's Horizon 2020 research and innovation programme under Grant Agreement n. 642224. The content of this article reflects only the authors' views and the European Union is not liable for any use that may be made of the information contained therein.
EU scale and beyond. These four elements guide the project workflow and are coordinated within the project management. The core of the FREEWAT platform will be the SID\&GRID framework in its QGIS desktop version. SID\&GRID (a GIS integrated hydrological model based on a modified version of MODFLOW 2005; Rossetto et al. 2013; Borsi et al. 2013) is an open source and public domain modelling platform firstly developed within the EU-POR FSE 2007-2013 Regione Toscana - Italy and then ported to the QGIS desktop through funds by Regione Toscana. SID\&GRID will be complemented with solute transport (also density dependent) capabilities in aquifers within the MARSOL (2014) FPVII project.

Details on FREEWAT can be found in the project website, and the references therein: http://www.freewat.eu
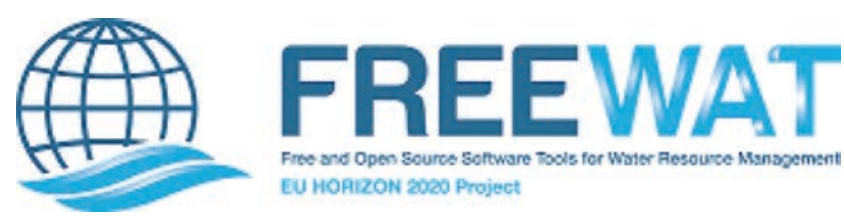

Fig. 1: The FREEWAT project logo.

\section{REFERENCES}

Borsi I., Rossetto R., Schifani C., Hill M.C. (2013). Modeling unsaturated zone flow and runoff processes by integrating MODFLOWLGR and VSF, and creating the new CFL package. Journal of Hydrology. Vol. 488, 2013, 33-47.

EC (1991) Directive 91/676/EEC of 12 December 1991 concerning the protection of waters against pollution caused by nitrates from agricultural sources

EC (2000) Directive 2000/60/EC of the European Parliament and of the Council, of 23 October 2000, establishing a framework for Community action in the field of water policy. Official Journal of the European Commission, L 327/1, 22.12.2000

EC (2006) Directive 2006/118/EC of the European Parliament and of the Council of 12 December 2006 on the protection of groundwater against pollution and deterioration.

MARSOL (2014). Demonstrating Managed Aquifer Recharge as a Solution to Water Scarcity and Drought. http://www.marsol.eu [last accessed 20 June 2015]

Refsgaard J.C., Højberg A.L., Møller I., Hansen M. and Søndergaard V. (2010). Groundwater Modeling in Integrated Water Resources Management-Visions for 2020. GROUND WATER 48, no. 5: 633-648.

Rossetto R., Borsi I., Foglia L. (2015) FREEWAT: FREE and open source software tools for WATer resource management, Rend. Online Soc. Geol. It., Vol. 35 (2015), pp. 252-255, doi: 10.3301/ ROL.2015.113.

Rossetto R., Borsi I., Schifani C., Bonari E., Mogorovich P., Primicerio M. (2013). SID\&GRID: Integrating hydrological modeling in GIS environment. Rendiconti Online Societa Geologica Italiana, Vol. 24, 282-283

Soncini-Sessa R., Editor(s) (2007). Developments in Integrated Environmental Assessment, Elsevier, Volume 1, Part A. 